\title{
Autism Spectrum Disorder: Review of Common challenging behaviors and appropriate intervention strategies
}

\author{
Jecinta Kerubo Nyakundi and George Mathenge Wairungu (Ph.D) \\ Department of Early Childhood and Special Needs Education, Kenyatta University, Kenya
}

\begin{abstract}
Autism Spectrum Disorder is a triad of disabilities with individuals exhibiting challenges in Social-Communication, repetitive behaviors and restricted activities and interests. Its etiology is not clear but, researchers point at a complex interaction between genetics and environment. There are more boys with ASD than girls at a ratio of 4 boys: 1girl. The disorder has been in an unprecedented rate of increase in the last few decades. Currently 1 in every 59 children has ASD (in USA). One of the greatest concerns by parents, speech therapists and educationists is how to deal with challenging behaviors in learners with ASD. The main aim of this paper is to consolidate research work and expert's opinion on what challenging behaviors entails and as well what intervention strategies exist.
\end{abstract}

To achieve this, an in-depth review of research findings published in renowned journals was done. A qualitative research approach was assumed utilizing Google scholar search engine to search for terms 'Autism Spectrum Disorders' 'challenging behaviors in ASD' and 'intervention strategies for challenging behaviors in ASD'. After this, the authors scanned through the abstracts of the articles to weigh their relevance in achieving the aim of the study. Only those articles that covered the relevant topics in an in-depth manner were considered for review. In this era of inclusive education, it is important that education is given a collaborative multidisciplinary team approach. Teaching learners with ASD or conducting therapy sessions can be difficult when challenging behaviors are exhibited. Behavior analysts are critically important in managing challenging behaviors but unfortunately we do not have enough of them to always be available when need arises.

It is important to train related education stakeholders on how to identify and intervene when challenging behaviors are exhibited. A one 'stop shop' is necessary as provided by this article. Most common challenging behaviors include physical and verbal aggression, elopement, pica, noncompliance, property destruction, self-injury, and incontinence. From the review, contemporary intervention strategies include Applied behavior analyses, use of Picture exchange communication system and Prompting and prompt fading. The bottom line of behavior management entails laying down behavior expectations and positively reinforcing it. Inappropriate behavior cannot change unless an alternative one is introduced and reinforced.

Key Word: Autism Spectrum Disorder, Challenging behavior, Intervention Strategis

\section{INTRODUCTION}

A utism was first described by Kanner in 1943 when he gave a detailed account of 11 children who exhibited unusual tendencies. They had challenges in language facilitation and were indifferent to other people. They also exhibited obsessive interests (Rylaarsdam \& GuemezGamboa, 2019). Autism spectrum disorder (ASD) is a complex neurodevelopmental disorder (Campisi et al., 2018), characterized by challenges in social communication skills, restricted interests and repetitive behaviors (Hodges, 2019). The repetitive behaviors are known as stimming and have a self-stimulating function. Usually, the behaviors involve repetitive sounds or movement (Alpert, 2021). The disorder is one of the most common neurodevelopmental disorders in the world (Campisi et al., 2018). Individuals exhibit impaired social reciprocal interaction (Faras, et al. 2009), poor ageappropriate play and failure to develop corresponding peer relationships (Memari et al., 2015), despite chronological age (Wairungu, 2020). Individuals vary in cognitive and social communicative abilities across the spectrum. Commonly some individuals have comorbid intellectual disability epilepsy or both. It is however not clear whether the three variables have an association (Permeggian, et al., 2019). Many people with ASD are also vulnerable to stress and anxiety (Stiegler, 2005).

ASD has a significant impact in multiple functional domains including adaptive functioning. Individuals with ASD need different levels of psychosocial support to achieve relative independence. In many cases, some individuals need continuous level of support (Campisi, 2018). In its most severe form, it could incapacitate an individual significantly making them require lifelong supportive care often in a chronic health care facility (Alpert, 2021). The disorder cuts across all races, ethnic groups and economic class (Campisi, 2018). There is no known propensity for any race, ethnicity or economic class (Alpert, 2021). In the last few decades, the disorder has been in an unprecedented rate of increase. The current prevalence rate is 1:59 in USA (Parmeggian et al., 2019). Further, there are more boys with ASD than girls in a ratio of 4: 1. Some Authorities indicate that girls have more severe symptoms than boys in most cases (Alpert, 2021).

In 2013, Diagnostic and statistical manual $5^{\text {th }}$ edition DSM-5 brought some changes in the criteria for diagnosis of ASD. It 
introduced the concept of spectrum. Previous separate pervasive developmental disorder (PDD) inclusive of autistic disorder, Asperger's Disorder, Childhood Disintegrative disorder and pervasive developmental 'disorder not otherwise specified' were all consolidated under one umbrella term 'Autism Spectrum Disorder'. By virtue of these changes, Rett Syndrome was recognized as a discrete neurological disorder. There is now Social (Pragmatic) Communication Disorder (SPCD) for those individuals exhibiting social communication deficiencies but lacking restrictive interests and repetitive behaviors (Hodges, et al., 2019). The term spectrum is used because some individuals with ASD have only a few or mild symptoms while others have many or severe symptoms (Wise, 2016. In DSMV there are five subcategories of ASD. They include autism with or without intellectual disability, autism with or without language impairment, autism accompanying another medical or generic condition, autism associated with another developmental, mental or behavioral disorder and finally autism combined with catatonia (Alpert, 2021).

Etipathogenesis of ASD is suspected to be multifactorial with researchers pointing at a complex interplay between genetics and environment, (Parmeggian, et al., 2019). While this is the case, researchers agree on some common risk factors. The risk factors include low birth weight, birth to old age parents, familial inheritance, genetic mutations leading to abnormalities of the brain, exposure to toxins, heavy metals or both, fetal exposure to specific medicine such as valproic acid and thalidomide and viral infections that affect the central nervous system (Alpert, 2021).

Diagnosis of ASD is mostly done before three years. Currently, it is purely anchored on clinical observation because there are no known biomarkers. The diagnoses, assumes a multidisciplinary approach involving speech and language pathologists, occupational therapists, psychologists (Alpert, 2021) family and caregivers.

\section{Characteristics of learners with Autism Spectrum Disorder}

As noted earlier, individuals with ASD have challenges in social communication skills, and as well exhibit restricted interest and repetitive behaviors. Individuals with ASD often face pervasive, all-encompassing challenges in almost every aspect of functioning.

\section{SOCIAL COMMUNICATION DIFFICULTIES}

Most individuals with ASD have challenges in communication and interpretation of their environment. This results in challenges with social interactions and processing information (Geller, 2016). It could also lead to challenging behaviors out of frustrations (Wairungu, 2020). Most common communication deficiencies include echolalia, monotonous speech, pronoun reversal, poor comprehensive skills, and at times complete lack of language. Individuals also have challenges understanding nonverbal communication and giving eye contact. Many have challenges with visual expressions and descriptive gestures (Campisi et al., 2018).
On the same note, majority exhibit poor quality, movement, poor orientation to verbal call, joint attention concerns and lack of social smile. Most language and social challenges are evident by age three (Parmeggian, et al., 2019).

Many individuals with ASD have a poor theory of mind being unable to appreciate that others have their own mind, feelings and beliefs. They are also unable to predict other people's intention or behavior. They may for example dwell on the same topic over and over again regardless of whether the communication partner is interested or not. They have challenges in turn taking in a conversation and commonly invade personal space. They are blind to most common unwritten rules of social interaction.

\section{Restricted repetitive behaviors}

Individuals with ASD exhibit restricted interest and repetitive behaviors. RRB plays functional self-stimulation and is associated with sensory processing disorders (Wairungu, 2020). The repetitive behaviors are diverse. Commonly, there is the simple stereotypic motor behaviors such as hand flapping and finger flipping. Other individuals exhibit use of repetitive speech known as echolalia and repetitive use of objects. Restricted behaviors may present themselves as resistance to change or highly restricted fixated interests, abnormal in intensity or focus. On the same note, some children may be hypo or hypersensitive to stimulus. They present an extreme response to stimuli such as noise touch and sound (Campisi et al., 2018).

\section{Challenging behaviors}

Challenging behaviors are quite a concern to family caregivers and educationists. They mainly occur because individuals have difficulties understanding the events occurring around them (Galler, 2016). On the same note, learners with ASD have difficulty in communicating their own wants and needs. This may lead to frustrations and in turn aggression as mentioned earlier. Precisely, challenging behaviors are associated with difficulties in expressing oneself, interpreting the environment, or understanding other people's communication. While this is the case, difficulties in sensory processing may also contribute to challenging behaviors in learners with ASD (Wairungu, 2020). Research indicates that the main risk factor for challenging behaviors is ASD severity, levels of cognitive, language impairments and medical comorbidity (Rattaz et al., 2018).

\section{Common Challenging Behaviors}

Challenging behaviors in learners with Developmental disabilities such as ASD include aggression, self-injury, stereotypic behavior, and withdrawal. It results out of interaction between personal and environmental factors (Pilling, et al., 2015). Prevalence of challenging behaviors increases with age during childhood; it reaches a peak during adolescence and young adulthood but eventually declines at late adulthood (Rattaz et al., 2018). Research indicates that individuals with ASD exhibit more challenging behaviors than 
typically developing peers, those with intellectual disabilities (of heterogeneous etiology) and psychiatric diagnosis only (Steenfeldt-Kristensen, 2020). The table below summarizes the key challenging behaviors in learners with ASD.

\section{Common challenging behaviors in individual with Autism} Spectrum Disorder

\begin{tabular}{|c|c|}
\hline Behavior & Common Features and reference \\
\hline $\begin{array}{c}\text { Restricted repetitive } \\
\text { behaviors }\end{array}$ & $\begin{array}{l}\text { Since description of ASD by Kanner in 1914 RRB } \\
\text { has been recognized as a core symptom of ASD. It } \\
\text { differentiates ASD from other developmental } \\
\text { disorders (Joseph et al., 2013). These may include } \\
\text { flappig, rocking among others (Peterson et al, 2018). } \\
\text { It can be a major barrier to adaptation and learning. } \\
\text { Many families report being stressed by RRB. } \\
\text { (Uljarevic et al., 2021) Individuals are preoccupied } \\
\text { with stereotyped and restricted patterns of interest, } \\
\text { with objects or parts of objects, adhere } \\
\text { nonfunctional routines and also exhibit repetitive } \\
\text { motor movement (Joseph et al., 2013). }\end{array}$ \\
\hline Pica & $\begin{array}{l}\text { Pica comes from a Latin word for magpic a bird } \\
\text { known to eat voraciously both food and nonfood } \\
\text { items alike ( Stiegler, 2005). It entails the act of } \\
\text { eating nonfood items inclusive of, soap, stones } \\
\text { buttons and papers (Miiter et al., 2015). It could lead } \\
\text { to gum disease, erosion of tooth enamel, dental } \\
\text { trauma oral lacerations, perforations and } \\
\text { obstruction (Stiegler, 2005). Its prevalence rate } \\
\text { among individuals with developmental disabilities } \\
\text { range from 9.2\% to } 25 \% \text { (Stiegler, 2016). The } \\
\text { condition is recognized by (Diagnostic and } \\
\text { Statistical Manual of Mental Disorders (DSM-5) as } \\
\text { the act of nonnutritive ingestion repeated for a } \\
\text { period of at least a month and is developmentally } \\
\text { inappropriate. Several theories attempt to explain } \\
\text { the phenomena, (Advani et al., 2014). They include } \\
\text { demands of tradition and acquired tastes in cultural } \\
\text { contests, presumptive neurobiological mechanisms } \\
\text { like iron deficiencies, physiological conditioning } \\
\text { and Central Nervous System Neurotransmission } \\
\text { (Blinder, 2008). This pathological craving and } \\
\text { eating of items that are non-nutritive can be harmful } \\
\text { to the child and could lead to legal suites against } \\
\text { speech therapists and educationists. It is usually } \\
\text { unnoticed and under reported (Mashao et al., 2021). } \\
\text { In absence of treatment it could lead to life } \\
\text { threatening obesity. Addiction of ingesting certain } \\
\text { items such as cigarette butts can lead to aggression } \\
\text { as individuals look for them (Stiegler, 2005). }\end{array}$ \\
\hline Aggressive behaviour & $\begin{array}{l}\text { This is behavior that threatens or could cause harm. } \\
\text { It could be either verbal (threatening cursing or } \\
\text { using words against another) or physical (hitting, } \\
\text { kicking, and biting) (Fitzpatrick, 2016). More than } \\
65 \% \text { of individuals with ASD exhibit aggressive } \\
\text { behaviors (Fiona et al., 2014). Aggression is } \\
\text { usually associated with communication deficits } \\
\text { (Giacomo, 2016), and poor theory of mind, } \\
\text { (Wairungu, 2020). The behavior disrupts therapy } \\
\text { session and learning in class and makes classroom } \\
\text { management difficulty. It is also a major cause of } \\
\text { stress for both teachers and parents. It also results in } \\
\text { fewer opportunities for independent functioning and } \\
\text { interpersonal relationships (Farmer et al., 2014). } \\
\text { Many residential placements are associated with } \\
\text { aggressive behaviors. Youths who are aggressive } \\
\text { experience more problems with repetitive behaviors, } \\
\text { family relations, and academic performance } \\
\text { compared to non-aggressive counterparts (Brown et }\end{array}$ \\
\hline
\end{tabular}

\begin{tabular}{|c|c|}
\hline & al, 2019) \\
\hline Elopement & $\begin{array}{l}\text { Elopement entails wandering to an unsafe } \\
\text { unsupervised place with no knowledge of care taker } \\
\text { (Mclaughlin, et al., 2020). Elopement rates are } \\
\text { estimated to be nearly four times higher in children } \\
\text { with ASD than typical peers (Veeraraghavan, 2017). } \\
\text { Half of the children with ASD in USA have eloped } \\
\text { or ever attempted to elope from adult supervisor at } \\
\text { least once (Mclaughlin, et al., 2020). Children with } \\
\text { limited communication abilities more likely have a } \\
\text { history of elopement (Pereira-Smith, 2019). Eloping } \\
\text { from adult supervision could sometimes end } \\
\text { catastrophically where individuals could drown get } \\
\text { injured or die for (whatever reasons) according to } \\
\text { Center for Disease Control (USA). }\end{array}$ \\
\hline Non -`compliance & $\begin{array}{l}\text { Children with ASD exhibit low levels of compliance } \\
\text { to request from caregivers and parents. It is not clear } \\
\text { when this starts (Ekas et al., 2017). It creates } \\
\text { barriers to their inclusion in regular school settings } \\
\text { (Imasaka et al., 2020). It can be purposeful, but at } \\
\text { times can result from lack of understanding, lack of } \\
\text { motivation, fatigue, or poor institutional planning } \\
\text { (Alberto \& Trautman, 2016). }\end{array}$ \\
\hline $\begin{array}{l}\text { Self-injurious } \\
\text { behavior }\end{array}$ & $\begin{array}{l}\text { These are behaviours used for inflicting harm on } \\
\text { oneself for purposes that are neither suicidal nor } \\
\text { socially sanctioned (Wells \& Axe, 2021). It includes } \\
\text { a series of aggressive behaviors that an individual } \\
\text { directs towards themselves which could potentially } \\
\text { result to physical injury, in form of tissue damage } \\
\text { (Matson \& Turygin 2012). They include head } \\
\text { banging, hand-to-head banging, body slamming, } \\
\text { hitting or punching oneself, eyeball pressing, biting } \\
\text { oneself, wound picking, and hair pulling } \\
\text { (Baghdadli, et al., 2003). It can also take a form of } \\
\text { self-mutilation which may involve cutting one's } \\
\text { skin, burning, or bone breaking. However, this is } \\
\text { less common in ASD not unless other psychiatric } \\
\text { conditions co-occur. Hand-hitting topography is the } \\
\text { most common (23\%), while self-cutting topography } \\
\text { is the least common (3\%) (Steenfeldt-Kristensen, } \\
\text { 2020). General prevalence rates of self-injurious } \\
\text { behavior vary from } 33 \text { to } 71 \% \text { (Baghdadli, et al., } \\
\text { 2003). It is also one of the reasons behind exclusion } \\
\text { from the mainstream schooling }\end{array}$ \\
\hline Incontinence & $\begin{array}{l}\text { This is defined as lack of voluntary control of } \\
\text { urination or defecation. Children with } \\
\text { developmental disabilities are more often affected } \\
\text { by incontinence than typically developing children } \\
\text { (Gontard et al., 2015, (Niemczyk, et al., 2018). } \\
\text { According to Greer (2012), it is common among } \\
\text { children with ASD whether they are schoolers or } \\
\text { not. Individuals with ASD may exhibit urge } \\
\text { incontinence, functional incontinence, bowel } \\
\text { incontinence or difficulties in toileting. It occurs due } \\
\text { to a compromised sensory processing between } \\
\text { peripheral and central nervous system (Yip et al., } \\
\text { 2013). }\end{array}$ \\
\hline Property destruction & $\begin{array}{l}\text { This is breaking or tearing of learning and session } \\
\text { materials (Mitter et al., 2015). It may involve } \\
\text { throwing, scratching, tearing, defacing belongings } \\
\text { (his or those belonging to others) etc. It is mostly } \\
\text { done to gain attention or to communicate needs or } \\
\text { feelings in learners with ASD. }\end{array}$ \\
\hline
\end{tabular}


Strategies of managing challenging behaviors in learners with $A S D$

Challenging behaviors make learning difficulty and at the same time compromises the quality of life of individuals with ASD. They need to be managed. It is important that educationist and caregivers learn how to identify the challenging behaviors and as well how to effectively intervene. Early intervention has been shown to improve cognition, adaptive behavior and also alter brain responses to social stimuli in learners with ASD (Schuetze, 2017). Individuals with ASD are quite diverse. Severity and degree of independence varies across the spectrum. No strategy therefore works across the spectrum. Intervention is individual -specific with best results being associated with collaborative multidisciplinary team approach. Adoption of various strategies such as applied behavior analysis has proven scientifically useful as discussed below.

\section{APPLIED BEHAVIORAL ANALYSIS}

Applied behavior analyses (ABA) was first described by Baer et al., in the year 1968. It was significantly distinguished from experimental analyses of behavior by its focus on addressing social impact. It aims at solving socially important problems in diverse social contexts. It has produced (remarkably) good social intervention in a host of fields including developmental disabilities like ASD (Slocum, et al., 2014). It is effective in assessing and treating disruptive behavior. ABA is a science rather than a specific treatment and it can be used to analyze a wide range of behaviors in individuals with and without ASD (Boelter, 2011). It is very effective in relieving Autism symptoms and developing valuable social skills (Westings, 2010). To achieve a fully changed behavior, the applied behavioral analysis therapy may need to be conducted one-onone or with small groups of children for peer tutoring (Cooper, 2017). Data collection is crucial before, during and after exhibition of challenging behaviour. Analyst must frequently do assessments (like checkups) on the learners in order to determine developmental progress (Gershom, 2017). When one technique fails, then another one could be chosen to achieve the set goals. The following considerations are critical while using ABA as an intervention.

Focus on Function. Every behavior exhibited in ASD has a function. The interventionist should focus not on the topography (i.e., what the behavior looks like) but function of behavior in order to effectively address it. In a situation where a child engages in aggressive behavior for example, the goal is to identify how the aggression serves the child (i.e., function) rather than on what the aggression looks like (e.g., hitting, biting) (Boelter, 2011).

Functional Behavioral Assessment: FBA is a broad term describing a number of different methods researchers and practitioners use to identify the reason a specific behavior occurs (Cooper et al., 2007). As noted earlier, learners with ASD exhibit certain behaviors purposively. In order to identify the function of a behavior, it is critical to conduct a functional behavior analyses. There are a variety of techniques that can be implemented when conducting a FBA. One could for example use an indirect method such as using questionnaires and conduction of interviews. Direct method through experimental analyses where live behavioral data is recorded can also be used (i.e., functional analysis). Common functions associated with challenging behavior include, wanting to gain attention, preferred items/activities, or escape from none preferred tasks or environmental setting (e.g., noisy environment). Further, access to some type of internal sensory (automatic) reinforcement could also be a reason (Boelter, 2011). Identifying the purpose helps come up with an effective behavior plan. A behavior plan is then written using a multidisciplinary team approach (Wairungu, 2020)

Function-Based Treatment. Once FBA has identified the function of the challenging behavior, a treatment plan targeting that function is developed. It is critical to teach an alternative behavior to the non desired behavior. This should aim at teaching the learner a socially acceptable way of earning the same reinforcer as that maintaining the undesired behavior. As this takes place, there should be simultaneous reinforcement where the desired behavior gets reinforced but the undesired behavior is ignored (Boelter, 2011). It is important to note that no behavior can change if no replacement behavior is in place. The undesired behavior is discouraged while the replacement behavior is reinforced (Wairungu, 2020).

\section{MODIFICATION STRATEGIES IN APPLIED BEHAVIOR ANALYSIS}

As noted above, Applied behavior analyses is critical in the intervention of challenging or disruptive behavior. After, specialized training, therapists and educationists should use the following techniques to manage behavior: reinforcement, positive behavior support, negative reinforcement, prompting and fading, use of picture exchange communications systems and social skill training. They are briefly explained below.

\section{Reinforcement}

Early behavior intervention forms an integral part of standard care in learners with ASD. It focuses on reducing undesired behavior while promoting occurrence of desired behavior. Example of undesired behaviors would be like echoing others while desired behaviors are eye contact which is a challenge in ASD (Schuetze, 2017). According to Prince (2013), the end result of reinforcement is to increase behavior occurrence unlike punishment procedures which are meant to decrease behavior.

Positive Behaviour Support: Research indicates that appropriate behavior and behavior expectation can be taught the same way academics are taught to a learner. Positive behavior support is an individualized problem solving strategy. It entails identifying the behavior concern and setting broad goals to address it. Data is then collected and analyzed to identify the patterns fueling the behavior. Strategies are then selected and delineated based on the patterns identified. 
They are integrated into a comprehensive plan. Finally, the plan is implemented across various setting. The outcomes are then progressively monitored (Hieneman, 2015).

PBS main features include lifestyle enhancement, collaboration, progress tracking, function based intervention and striving for contextual fit. PBS and positive reinforcement emerged as a response to immense concerns against use of aversive and humiliating procedures to manage behavior. It was considered cruel to punish a learner for violation of rules. Advocacy for inclusive home, school, work, recreational, and community settings for individuals with disabilities also contributed to its adoption (Lucyshyn et al., 2014).

PBS has proven to be more effective than the traditional method of punishment. According to Mclntyre et al., (2016), a learner with social and behavioral disabilities may not be informed on how to respond in certain circumstances. Learners are able to behave appropriately if they know the behavior expected of them. Unlike typically developing children, learners with developmental disabilities like ASD lack this intrinsic skill. They do not know how to vary their behaviors across contexts. Positive behavior support does not ignore the challenging behavior but its focus is not punishment but changing it by teaching behavior expectations. A replacement behavior is introduced and reinforced. Appropriate consequences help motivate long term change of behavior. In the model, routines and standards are structurally set. Learners know what to do once they enter class (or therapy session) for example, during task and during break. Communication on expected behavior is also done concisely and with respect. Corrections are accompanied with habitual praise. This cultivates safe positive learning environment.

\section{Negative Reinforcement}

According to Prince (2013), negative reinforcement occurs when a certain stimulus (usually aversive) is removed after a particular behavior is exhibited. This increases the possibility of the desired behavior reoccurring again. There is desire of avoiding the negative consequence. Negative reinforcement should however not be mistaken for punishment. In negative reinforcement, a behavior is reinforced and its chance of reoccurring increased while in punishment a behavior is being discouraged. Example, a child cleans dishes (behavior) on time in order to avoid being yelled at (aversive stimulus). On the other hand, punishment is a process by which a consequence immediately follows a behavior which decreases chances of the behavior reoccurring in future. Just like reinforcement, a stimulus can be added (positive punishment) or removed (negative punishment). It is important to note that in the current world of human rights, punishment is abhorrent and out of tune (especially) in the field of disabilities. It should not be used to manage behavior.

\section{Prompting and Prompt Fading}

Children with Autism Spectrum Disorders (ASD) in many cases require prompting in order to learn new behaviors. They also need prompt-fading to generalize knowledge learnt in different contexts. It is critical to transfer stimulus control from the prompt to the naturally occurring discriminative stimuli (Cengher et al., 2016). According to Victor (2016), prompts are those specific verbal cues used to encourage behaviors. They are gentle reminders used in correcting a certain behavior. Visual cues are less direct and might be a gesture or a direct look on the eyes of the learners with ASD. Prompts are eventually faded to encourage an individual to behave appropriately but independently (Juan, 2015). The prompts can be helpful since they are typically not intimidating or accusatory.

\section{Use of Picture Exchange Communication Systems}

Indiana resource center for Autism (website) describes picture exchange communication Systems as a modified ABA therapy targeting early nonverbal symbolic communication training.

ASD learners have a challenge in giving expressions on their feelings and wants (Angela, 2016). Research indicates that majority of learners with ASD enter formal programs with behaviors that indicate challenges in communication. Most common socially acceptable form of communication (in typical population) is speech. It is commonly deficient in ASD learners (Bondy \& Frost 1998). A critical goal of teaching children with ASD is improved communication. Experts opine that many behaviors exhibited by learners with ASD have communication intent. PECS is meant to fill that gap.

It was first developed in Delaware Autistic Program. Learners are trained to give a communication partner a picture in exchange for an item (Collet-Klingenberg, 2008). The therapists systematically keep building behavior changing skills through the use of pictures as communication devices. Since many challenging behaviors are associated with communication difficulties, PECS facilitates communication and therefore discourages use of aggression or any undesirable behavior to express oneself.

\section{SOCIAL SKILL TRAINING}

Social skills and behavior are highly correlated in both typically and atypically developing children. There is considerable evidence that social skill deficits are integral to many emotional and behavioral problems (Spence, 2003). Social skills are a subset of more general category of interpersonal intelligence. This is the ability to understand and interact with other people (Campbell, 2008). As noted earlier, ASD is a triad of disabilities with Social skill deficit being one of them. The others are challenging behaviors and communication deficit (Wairungu, 2020). Social skill deficit leads to inappropriate behaviors in diverse social contexts.

Due to challenges with the theory of mind, ASD learners are unable to predict other people's minds or behavior. They are also unable to know what is expected of them in various social contexts. They need to be motivated to have meaningful interactions with others. One research based strategy of doing this is Social Skill Training (SST). 
It aims at increasing ability to perform key social behaviors important in achieving success in social situations. The strategies include instructions, modelling, behavior rehearsal, feedback and reinforcement (Spence, 2003). Traditionally, Programs have relied on a child-facilitator interaction and the need for trained facilitators is one of the primary barriers to intervention. In the modern days however, technology has been incorporated. Novel methods of SST delivery include the use of Behavioral Intervention Technologies (BITs), aimed at producing positive behavioral and psychological changes as either an adjunct to or substitute to face-to-face interventions. Not much information is available on how these programs perform compared to traditional face-to-face training (_Soares et al., 2020).

According to Cooper (2017), young learners with ASD easily learn social skills much better as compared to adults. Early intervention is therefore critical (Wairungu, 2020).

\section{Addressing pica challenges}

As noted earlier Pica can be quite harmful depending with what the child introduces into the digestive system. Addressing it is quite critical for the safety of the child and to avoid possible legal suites against educationists and practitioners.

To start with, it is important for the teacher or care giver to keep a record of each time a child eats the non-edibles, the context and any information they find crucial. If Pica is associated with iron or zinc deficiency, appropriate food supplement is recommended. Ferrous Sulphate is commonly prescribed but it has significantly serious side effects. This includes gastrointestinal discomfort, bloating and other discomforts. An alternative supplement known as ferrous gluconate is preferred. It has fewer side effects. Ascorbic acid supplement is also known to enhance iron absorption (Advani, 2014). Apart from the above, applied behavior analysis has been known to be very effective in addressing pica problems by providing aversive stimuli (Matson, 2013) and overcorrection. Finally, counselling and psychotherapy have also been proved effective (Stiegler, 2005).

\section{Addressing non suicidal self-injury behaviors}

As noted earlier, self-injurious behavior can be quite catastrophic. It is harmful to the affected individual but at the same time induces fear to other individuals in the same classroom or environment. A number of intervention strategies exist. Literature from renowned journal articles gives a number of approaches. To start with, a structured collaborative therapeutic relation has proven effective. Motivation for change by applying ABA discussed earlier has also been used as an intervention successfully. Emotion Regulation group therapy and manual assisted cognitive therapy are also a recommended approaches. Finally, medications targeting the serotonergic, dopaminergic and opioid systems also have demonstrated some benefits as well (Turner et al., 2014).

\section{Addressing incontinence}

Incontinence is challenging and needs to be addressed for the good of the affected child, those around her and hygiene in general. It could lower the dignity and self-esteem of the affected individual. Toilet training is quite critical in addressing the incontinence challenge. This is better done using ABA discussed earlier. Individuals need to be reminded routinely (to use the bathroom) and reinforced promptly for appropriate response (Smith, 2000). It is important to work with the family medical doctor and occupational therapists for appropriate medical intervention.

\section{CONCLUSION}

Challenging behaviours are many and quite common in learners with ASD. Research indicates that this is quite a concern in many families. Since ASD is polymorphic in characteristics, challenging behaviors are quite diverse. On the same note, no intervention works equally across the spectrum. It is critical that a multidisciplinary approach is used while addressing the challenges.

\section{REFERENCES}

[1]. Advani, S., Kochhar, G., Chachra, S., \& Dhawan, P. (2014). Eating everything except food (PICA): A rare case report and review. Journal of International Society of Preventive \& Community Dentistry, 4(1), 1-4. https://doi.org/10.4103/22310762.127851

[2]. Alberto, P., \& Troutman, A. C. (2016). Applied behavior analysis for teachers (pp. 1-474). Upper Saddle River, NJ: Pearson Merrill Prentice Hall.

[3]. Alpert, J.S (2021). Autism: A Spectrum Disorder. The American Journal of Medicine 134 (6), 701-702

[4]. Arora, P. G., Alvarez, K., Huang, C., \& Wang, C. (2021). A Three-Tiered Model for Addressing the Mental Health Needs of Immigrant-Origin Youth in Schools. Journal of immigrant and minority health, 23(1), 151-162. https://doi.org/10.1007/s10903020-01048-9

[5]. Baer, D. M., Wolf, M. M., \& Risley, T. R. (2018). Some current dimensions of applied behavior analysis. Journal of applied behavior analysis, $1(1), 91$.

[6]. Baghdadli, A., Pascal, C., Grisi, S., \& Aussilloux, C. (2003). Risk factors for self-injurious behaviours among 222 young children with autistic disorders. Journal of Intellectual Disability Research, 47, 622-627.

[7]. Blinder B.J., \& Salama, C. (2008). An Update on Pica: Prevalence, Contributing Causes, and Treatment. Psychiatric, times 25, 6 .

[8]. Boelter, E.W. (2011). Disruptive Behavior and Autism Spectrum Disorder. Seattle Childrens Research. The Autism Blog. https://theautismblog.seattlechildrens.org/whats-the-function/

[9]. Bondy, A.S \& Frost, A.L (1998). The Picture Exchange Communication System. Focus on Autistic Behaviour (9) 3

[10]. Brown, C. E., Borduin, C. M., Dopp, A. R., \& Mazurek, M. O. (2019). The social ecology of aggression in youths with autism spectrum disorder. Autism research : official journal of the International Society for Autism Research, 12(11), 1636-1647. https://doi.org/10.1002/aur.2157

[11]. Brown, C. E., Borduin, C. M., Dopp, A. R., \& Mazurek, M. O. (2019). The social ecology of aggression in youths with autism spectrum disorder. Autism research : official journal of the International Society for Autism Research, 12(11), 1636-1647. https://doi.org/10.1002/aur.2157 
[12]. Brown,C., Bordan, C.M. Dopp, A.R. \& Mazurek M. (2019). The social ecology in youths of aggression with Autism Spectrum Disorder . Autism Research 12 (1) DOI: 10.1002/aur.2157

[13]. Campisi, L., Imran, N., Nazeer, A., Skokauskas, N., \& Waqar, A. (2018), Autism spectrum disorder. British Medical Bulletin, 127, 1, 91-100, https://doi.org/10.1093/bmb/ldy026

[14]. Cengher, M., Shamoun, K., Moss, P., Roll, D., Feliciano, G., \& Fienup, D. M. (2015). A Comparison of the Effects of Two Prompt-Fading Strategies on Skill Acquisition in Children with Autism Spectrum Disorders. Behavior analysis in practice, 9(2), 115-125. https://doi.org/10.1007/s40617-015-0096-6

[15]. Center for disease control and prevention. Disability and Safety: Information on Wandering

[16]. https://www.cdc.gov/ncbddd/disabilityandsafety/wandering.html

[17]. De Giacomo, A., Craig, F., Terenzio, V., Coppola, A., Campa, M. G., \& Passeri, G. (2016). Aggressive Behaviors and Verbal Communication Skills in Autism Spectrum Disorders. Global pediatric health, 3, 2333794X16644360. https://doi.org/10.1177/2333794X16644360

[18]. De Giacomo, A., Craig, F., Terenzio, V., Coppola, A., Campa, M. G., \& Passeri, G. (2016). Aggressive Behaviors and Verbal Communication Skills in Autism Spectrum Disorders. Global Pediatric Health. https://doi.org/10.1177/2333794X16644360

[19]. Dunlap, G., \& Fox, L. (2017). Parent-professional partnerships: A valuable context for addressing challenging behaviours. International Journal of Disability, Development and Education, 54(3), 273-285.

[20]. Ekas, N. V., McDonald, N. M., Pruitt, M. M., \& Messinger, D. S. (2017). Brief Report: The Development of Compliance in Toddlers at-Risk for Autism Spectrum Disorder. Journal of autism and developmental disorders, 47(4), 1239-1248. https://doi.org/10.1007/s10803-016-2984-1

[21]. Ekas, N. V., McDonald, N. M., Pruitt, M. M., \& Messinger, D. S. (2017). Brief Report: The Development of Compliance in Toddlers at-Risk for Autism Spectrum Disorder. Journal of autism and developmental disorders,47(4), 1239-1248. https://doi.org/10.1007/s10803-016-2984-1

[22]. Faras, H., Al Ateeqi, N., \& Tidmarsh, L. (2010). Autism spectrum disorders. Annals of Saudi medicine, 30(4), 295-300. https://doi.org/10.4103/0256-4947.65261

[23]. Farmer, C., Butter, E., Mazurek, M. O., Cowan, C., Lainhart, J., Cook, E. H., DeWitt, M. B., \& Aman, M. (2015). Aggression in children with autism spectrum disorders and a clinic-referred comparison group. Autism : The international journal of research and practice, 19(3), 281-291. https://doi.org/10.1177/1362361313518995

[24]. Fitzpatrick, S. E., Srivorakiat, L., Wink, L. K., Pedapati, E. V., \& Erickson, C. A. (2016). Aggression in autism spectrum disorder: presentation and treatment options. Neuropsychiatric disease and treatment, 12, 1525-1538. https://doi.org/10.2147/NDT.S84585

[25]. Fitzpatrick, S. E., Srivorakiat, L., Wink, L. K., Pedapati, E. V., \& Erickson, C. A. (2016). Aggression in autism spectrum disorder: presentation and treatment options. Neuropsychiatric disease and treatment, 12, 1525-1538. https://doi.org/10.2147/NDT.S84585

[26]. Fitzpatrick, S. E., Srivorakiat, L., Wink, L. K., Pedapati, E. V., \& Erickson, C. A. (2016). Aggression in autism spectrum disorder: presentation and treatment options. Neuropsychiatric disease and treatment, 12, 1525-1538. https://doi.org/10.2147/NDT.S84585

[27]. Friman P. C. (2010). COOPER, HERON, AND HEWARD'S APPLIED BEHAVIOR ANALYSIS (2ND ED.): CHECKERED FLAG FOR STUDENTS AND PROFESSORS, YELLOW FLAG FOR THE FIELD. Journal of Applied Behavior Analysis, 43(1), 161-174. https://doi.org/10.1901/jaba.2010.43161

[28]. Geller, E. S. (2015). Applied behavior analysis and social marketing: An integration for environmental preservation. Journal of social issues, 45(1), 17-36.

[29]. Gio, R. M. (2008). Applied behavior analysis treatment of autism: The state of the art. Child and adolescent psychiatric clinics of North America, 17(4), 821-834.
[30]. Greer, R. D. (2002). Designing teaching strategies: An applied behavior analysis systems approach. Academic Press.

[31]. Gregory, C. (2008). Social Skills Training: Evaluating its Effectiveness for Students with Learning Disabilities, Emotional, and Behavioral Disorders. Journal of the American Academy of Special Education Professionals, 5-25

[32]. Gresham, F. M., Gansle, K. A., \& Noell, G. H. (2017). Treatment integrity in applied behavior analysis with children. Journal of Applied Behavior Analysis, 26(2), 257-263.

[33]. Hastings, R. P. (2003). Behavioral adjustment of siblings of children with autism engaged in applied behavior analysis early intervention programs: The moderating role of social support. Journal of autism and developmental disorders, 33(2), 141-150.

[34]. Hieneman M. (2015). Positive Behavior Support for Individuals with Behavior Challenges. Behavior analysis in practice, $8(1)$, 101-108. https://doi.org/10.1007/s40617-015-0051-6

[35]. Indiana Resource Center for Autism (IRCA) .https://www.iidc.indiana.edu/irca/index.html

[36]. Imasaka, T., Lee, P. L., Anderson, A., Wong, C. W. R., Moore, D. W., Furlonger, B., \& Busacca, M. (2020). Improving compliance in primary school students with Autism Spectrum Disorder. Journal of Behavioral Education, 29, 763786. https://doi.org/10.1007/s10864-019-09346-5

[37]. Iwata, B. A. (2017). Negative reinforcement in applied behavior analysis: An emerging technology. Journal of Applied Behavior Analysis, 20(4), 361-378.

[38]. Johnson, K. A., Vladescu, J. C., Kodak, T., \& Sidener, T. M. (2017). An assessment of differential reinforcement procedures for learners with autism spectrum disorder. Journal of Applied Behavior Analysis, 50(2), 290-303. Joseph, L., Thurm, A., Farmer, C., \& Shumway, S. (2013). Repetitive behavior and restricted interests in young children with autism: comparisons with controls and stability over 2 years. Autism research : official journal of the International Society for Autism Research,6(6), 584-595. https://doi.org/10.1002/aur.1316

[39]. Lucyshyn, J. M. , Binnendyk, L., Fossett, B., Cheremshynski, C., Lohrmann, S., Elkinson, L., Miller, L. (2009). Toward an ecological unit of analysis in behavioral assessment and intervention with families of children with developmental disabilities. In: Sailor W, Dunlap G, Sugai G, Horner R, editors. Handbook of positive behavior support. Baltimore: Paul H. Brookes; pp. 73-106. [Google Scholar]

[40]. Lucyshyn, J.M., Dunlap, G., \& Freeman R. (2014). A historical perspective on the evolution of positive behavior support as a science-based discipline. In: Brown F, Anderson J, De Pry R, editors. Individual positive behavior supports: A standards-based guide to practices in school and community-based settings. Baltimore: Paul H. Brookes; . pp. 3-25. [Google Scholar]

[41]. Mashao, U., Ekosse, G. I., Odiyo, J., \& Bukalo, N. (2021). Geophagic practice in Mashau Village, Limpopo Province, South Africa. Heliyon, 7(3), https://doi.org/10.1016/j.heliyon.2021.e06497

[42]. Matson, J. L., \& Turygin, N. C. (2012). How do researchers define behavior? Research in Developmental Disabilities, 33, 10211026.

[43]. Matson, J. L., Hattier, M. A., Belva, B., \& Matson, M. L. (2013). Pica in persons with developmental disabilities: approaches to treatment. Research in developmental disabilities, 34(9), 25642571. https://doi.org/10.1016/j.ridd.2013.05.018

[44]. McIntyre, L. L., Gresham, F. M., DiGennaro, F. D., \& Reed, D. D. (2017). Treatment integrity of school-based interventions with children in the journal of applied behavior analysis 19912005. Journal of applied behavior analysis, 40(4), 659-672.

[45]. McLaughlin, L., Rapoport, E., Keim, S. A., \& Adesman, A. (2020). Wandering by Children with Autism Spectrum Disorders: Impact of Electronic Tracking Devices on Elopement Behavior and Quality of Life. Journal of developmental and behavioral pediatrics : JDBP, 41(7), 513-521. https://doi.org/10.1097/DBP.0000000000000817 
[46]. Memari, A. H., Panahi, N., Ranjbar, E., Moshayedi, P., Shafiei, M., Kordi, R., \& Ziaee, V. (2015). Children with Autism Spectrum Disorder and Patterns of Participation in Daily Physical and Play Activities. Neurology research international, 2015, 531906. https://doi.org/10.1155/2015/531906

[47]. Mitteer, D. R., Romani, P. W., Greer, B. D., \& Fisher, W. W. (2015). Assessment and treatment of pica and destruction of holiday decorations. Journal of applied behavior analysis, 48(4), 912-917. https://doi.org/10.1002/jaba.255

[48]. Niemczyk, J., Wagner, C., \& von Gontard, A. (2018). Incontinence in autism spectrum disorder: a systematic review. European child \& adolescent psychiatry, 27(12), 15231537. https://doi.org/10.1007/s00787-017-1062-3

[49]. Parmeggiani, A., Corinaldesi, A. \& Posar, A. Early features of autism spectrum disorder: a cross-sectional study. Ital $J$ Pediatr 45, 144 (2019). https://doi.org/10.1186/s13052-019-07338

[50]. Patra, S., \& Kar, S. K. (2021). Autism spectrum disorder in India: a scoping review. International review of psychiatry (Abingdon, England), 33(1-2),

$81-112$ https://doi.org/10.1080/09540261.2020.1761136

[51]. Pereira-Smith, S., Boan, A., Carpenter, L. A., Macias, M., \& LaRosa, A. (2019). Preventing elopement in children with autism spectrum disorder. Autism research : official journal of the International Society for Autism Research, 12(7), 1139-1146. https://doi.org/10.1002/aur.2114

[52]. Pilling, S., Marcus, E., Whittington, C., \& Murphy, G. (2015). Challenging behaviour and learning disabilities: Summary of NICE guidance. BMJ: British Medical Journal, 350. Retrieved July 17, 2021, from https://www.jstor.org/stable/26520872

[53]. Prince,K. (2013) Difference between Positive/Negative Reinforcement and Positive/Negative Punishmenthttps://bcotb.com/the-difference-betweenpositivenegative-reinforcement-and-positivenegative-punishment/

[54]. Rattaz, C., Michelon, C., Munir, K., \& Baghdadli, A. (2018) Challenging behaviours at early adulthood in autism spectrum disorders: topography, risk factors and evolution. Journal of intellectual disability research : JIDR,62(7), 637-649. https://doi.org/10.1111/jir.12503

[55]. Schuetze, M., Rohr, C. S., Dewey, D., McCrimmon, A., \& Bray, S. (2017). Reinforcement learning in autism spectrum disorder. Frontiers in Psychology, 8, Article 2035. https://doi.org/10.3389/fpsyg.2017.02035

[56]. Simpson, R. L., de Boer-Ott, S. R., \& Smith-Myles, B. (2013). Inclusion of learners with autism spectrum disorders in general education settings. Topics in language disorders, 23(2), 116-133.

[57]. Slocum, T. A., Detrich, R., Wilczynski, S. M., Spencer, T. D., Lewis, T., \& Wolfe, K. (2014). The Evidence-Based Practice of Applied Behavior Analysis. The Behavior analyst, 37(1), 41-56. https://doi.org/10.1007/s40614-014-0005-2

[58]. Smith, L., Smith, P., \& Kwok Yi Lee, S. (2000). Behavioural treatment of urinary incontinence and encopresis in children with learning disabilities: Transfer of stimulus control. Developmental Medicine \& Child Neurology, 42(4), 276-279. doi:10.1017/S0012162200000475

[59]. Rylaasdam \& Guemez-Gamboa (2019). Genetic causes and modifiers of Autism Spectrum Disorder. Frontiers in cellular neuroscience $\quad(13) \quad$,385 , https://www.frontiersin.org/article/10.3389/fncel.2019.00385

[60]. Soares, E. E., Bausback, K., Beard, C. L., Higinbotham, M., Bunge, E. L., \& Gengoux, G. W. (2020). Social Skills Training for Autism Spectrum Disorder: a Meta-analysis of In-person and Technological Interventions. Journal of technology in behavioral science, 1-15. Advance online publication. https://doi.org/10.1007/s41347-020-00177-0

[61]. Spence, S.H. (2003). Social Skills Training with Children and Young People: Theory, Evidence and Practice Child and Adolescent Mental Health Volume (8) 2, 84-96.

[62]. Steenfeldt-Kristensen, C., Jones, C.A. \& Richards, C. The Prevalence of Self-injurious Behaviour in Autism: A Meta- analytic Study. J Autism Dev Disord 50,3857-3873 (2020). https://doi.org/10.1007/s10803-020-04443-1

[63]. Stiegler LN. Understanding Pica Behavior: A Review for Clinical and Education Professionals. Focus on Autism and Other Developmental Disabilities. 2005;20(1):27-38. doi:10.1177/10883576050200010301

[64]. Turner, B. J., Austin, S. B., \& Chapman, A. L. (2014). Treating nonsuicidal self-injury: a systematic review of psychological and pharmacological interventions. Canadian journal of psychiatry. Revue canadienne de psychiatrie,59(11), 576-585. https://doi.org/10.1177/070674371405901103

[65]. Veeraraghavan J. I. (2017). Elopement in Children With Autism Spectrum Disorder The American Journal of Psychiatry Residents' Journal 12 (2). 15-17.

[66]. Vicker B. (2021). What is Picture Exchange Communication Systems. Retrieved from https://www.iidc.indiana.edu/irca/articles/what-is-the-pictureexchange-communication-system-or-pecs.html

[67]. Wahler, R. G., \& Fox, J. J. (2015). Setting events in applied behavior analysis: Toward a conceptual and methodological expansion. Journal of Applied Behavior Analysis, 14(3), 327-338.

[68]. Wairungu, G.M. (2020). Applied Behavior Analysis as an Intervention Strategy in Learners with Autism Spectrum Disorder. International journal of research and scientific innovation 5 (5)

[69]. Wairungu, G.M., (2020). Sensory Processing Disorder in individuals with Autism Spectrum Disorder. International Journal of Research and Scientific (5), 2.

[70]. Westling, D. L. (2010). Teachers and challenging behavior: Knowledge, views, and practices. Remedial and Special Education, 31(1), 48-63.

[71]. Whalon, K., \& Hart, J. E. (2011). Adapting an evidence-based reading comprehension strategy for learners with autism spectrum disorder. Intervention in School and Clinic, 46(4), 195-203.

[72]. Yip, J., Powers, B., \& Kuo, F. (2013). The Sensory Experience of Toilet Training and Its Implications for Autism Intervention. In Fitzgerald, M. (Ed). Recent Advances in Autism Spectrum Disorders - Volume II. InTech. doi: 10.5772/50854 